\title{
An alternative measure of positive correlation
}

DOI:

10.1080/0020739X.2018.1520931

\section{Document Version}

Accepted author manuscript

Link to publication record in Manchester Research Explorer

\section{Citation for published version (APA):}

Nadarajah, S., Chu, J., \& Chan, S. (2018). An alternative measure of positive correlation. International Journal of Mathematical Education in Science and Technology, 1-4. https://doi.org/10.1080/0020739X.2018.1520931

\section{Published in:}

International Journal of Mathematical Education in Science and Technology

\section{Citing this paper}

Please note that where the full-text provided on Manchester Research Explorer is the Author Accepted Manuscript or Proof version this may differ from the final Published version. If citing, it is advised that you check and use the publisher's definitive version.

\section{General rights}

Copyright and moral rights for the publications made accessible in the Research Explorer are retained by the authors and/or other copyright owners and it is a condition of accessing publications that users recognise and abide by the legal requirements associated with these rights.

\section{Takedown policy}

If you believe that this document breaches copyright please refer to the University of Manchester's Takedown Procedures [http://man.ac.uk/04Y6Bo] or contact uml.scholarlycommunications@manchester.ac.uk providing relevant details, so we can investigate your claim.

\section{OPEN ACCESS}




\title{
An alternative measure of positive correlation ${ }^{1}$
}

\author{
by \\ Saralees Nadarajah, Jeffrey Chu, Stephen Chan \\ University of Manchester, Manchester M13 9PL, UK
}

\begin{abstract}
A correlation coefficient taking positive values is introduced. It is more easily understood than other correlation measures especially in social science contexts. Estimation issues are addressed. A data application is given.
\end{abstract}

Keywords: Complete dependence; Confidence interval; Independence

\section{Introduction}

The meaning of the correlation coefficient is quite mysterious for statistically unsophisticated readers, causing much confusion in the popular communication of social science results. Two misunderstandings are most common: i) a nearly-dichotomous reading in which the phrase "is correlated with" is interpreted as a nearly perfect association; ii) a linear interpretation of the strength of the relationship, which differs sharply from the standard usage of $r^{2}$ in statistics as a measure of predictive gain. In contrast, the relative frequency of predictably ordered pairs in a bivariate population is easily understood. We illustrate this by three examples.

- The first is due to Kahneman (2012, page 205) and is on the correlation between measures of the success of a firm and of the quality of its CEO. Suppose you consider many pairs of firms. The two firms in each pair are generally similar, but the CEO of one of them may be better than the other. How often will you find that the firm with the stronger CEO is the more successful of the two?

- Another example is based on football. We may be interested in the correlation between the final position that a premier league team finishes in (at the end of a season) and the number of goals conceded by that team throughout the whole season. One may assume that if a premier league team maintains a clean sheet for that season, then that team will be at the top of the table at the end of the season. However, this is not always the case. How often will you find that a team which finishes towards the top of the premier league table concedes fewer goals during season?

- The third example is based on the correlation between the age of CEOs and their corresponding company's price earnings ratio. Can we assume that the older the CEO, the more knowledgeable and experienced one may expect him to be, and thus the greater the positive effect he will have on the company, which may lead to a more favourable price earnings ratio?

\footnotetext{
${ }^{1}$ This paper was directly motivated by an idea suggested by Professor Daniel Kahneman of Princeton University. Professor Kahneman won the Nobel Prize in Economics in 2002.
} 
In the first and third examples, a statement that only 60 percent of pairs of companies are positively ordered (with 50 percent due to chance) is expected to be more meaningful to the lay reader than a report that the correlation between the variables is 0.30 . In the second example, a statement that only 60 percent of pairs of football teams are positively ordered is expected to be more meaningful than a report that the correlation between the variables is 0.30 . We shall return to one of these examples in Section 3.

Suppose $(X, Y)$ are the two variables of interest. Let $\left(X_{1}, Y_{1}\right)$ and $\left(X_{2}, Y_{2}\right)$ be independent and identical copies of $(X, Y)$. Then the probability that $X_{1}$ and $X_{2}$ are ordered like $Y_{1}$ and $Y_{2}$ (that is, if $X_{1}>X_{2}$ then $Y_{1}>Y_{2}$ and similarly if $X_{1}<X_{2}$ then $\left.Y_{1}<Y_{2}\right)$ is

$$
P=\operatorname{Pr}\left[\left(X_{1}-X_{2}\right)\left(Y_{1}-Y_{2}\right)>0\right] .
$$

Obviously, $0 \leq P \leq 1$. If $X$ and $Y$ are completely dependent random variables then $P=1$. If $X$ and $Y$ are completely negatively dependent random variables then $P=0$.

The concept leading to (1) is connected to measures of concordance and measures of association (Balakrishnan et al., 2005; Berry et al., 2014). But we are not aware of any probability based measure taking the form of (1). To the best of our knowledge, the measure given by (1) is new.

The aim of this note is to introduce (1) as a more meaningful measure (although it can only take non-negative values) than other correlation coefficients. Section 2 discusses procedures for estimating (1). Section 3 provides a real data illustration of (1).

\section{Estimation}

Suppose $\left(x_{1}, y_{1}\right),\left(x_{2}, y_{2}\right), \ldots,\left(x_{n}, y_{n}\right)$ are observations on $(X, Y)$, assumed to be a random sample. There are $\left(\begin{array}{l}n \\ 2\end{array}\right)$ possible ordered pairs $\left(x_{i}, y_{i}\right),\left(x_{j}, y_{j}\right), i<j$. Using these ordered pairs, $P$ can be estimated by

$$
\widehat{P}=\frac{1}{\left(\begin{array}{c}
n \\
2
\end{array}\right)} \sum_{i=1}^{n} \sum_{j=i+1}^{n} I\left\{\left(x_{i}-x_{j}\right)\left(y_{i}-y_{j}\right)>0\right\},
$$

where $I\{A\}$ denotes the indicator function. Confidence intervals for $P$ can be based on various methods, as shown in Table 1. The first four of the listed methods are based on approximations. The last one is an exact method. Note that (2) can take only rational number values between 0 and 1. 


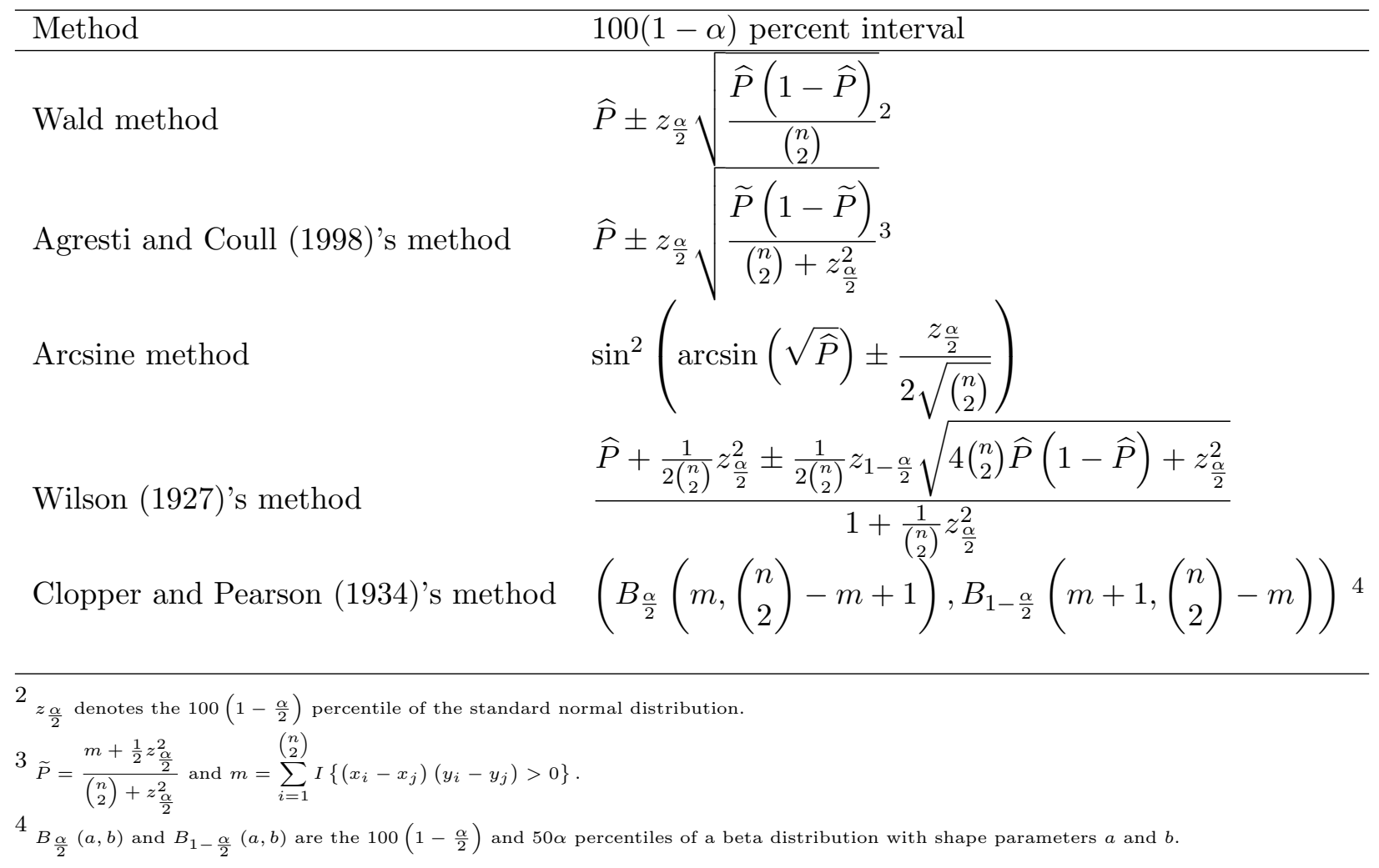

Table 1: Confidence intervals for $P$.

Finally, an approximate $100(1-\alpha)$ percent interval for $P$ based on the jackknife method can be described as follows:

- estimate (2) say $\widehat{P}_{1}$ by removing the first observation from the random sample, that is, $\left(x_{2}, y_{2}\right),\left(x_{3}, y_{3}\right), \ldots,\left(x_{n}, y_{n}\right)$

- estimate (2) say $\widehat{P}_{2}$ by removing the second observation from the random sample, that is, $\left(x_{1}, y_{1}\right),\left(x_{3}, y_{3}\right), \ldots,\left(x_{n}, y_{n}\right)$

$\vdots$

$\vdots$

- estimate (2) say $\widehat{P}_{n}$ by removing the last observation from the random sample, that is, $\left(x_{1}, y_{1}\right),\left(x_{2}, y_{2}\right), \ldots,\left(x_{n-1}, y_{n-1}\right)$;

- estimate the empirical cumulative distribution function say $\widehat{G}(\cdot)$ of $\widehat{P}_{1}, \widehat{P}_{2}, \ldots, \widehat{P}_{n}$;

- the confidence interval for $P$ can be estimated by

$$
\left(\widehat{G}^{-1}\left(\frac{\alpha}{2}\right), \widehat{G}^{-1}\left(1-\frac{\alpha}{2}\right)\right)
$$

where $\widehat{G}^{-1}(\cdot)$ denotes the inverse function of $\widehat{G}(\cdot)$. 


\section{Real data application}

Here, we return to one of the three examples discussed in Section 1 . The variables are $X=$ age of the CEO in 2003 and $Y=$ price earnings ratio in 2003 for twenty companies. The data on these variables are listed in Table 2. The price earnings ratio is the ratio for valuing a company that measures its current share price relative to its per-share earnings. It can be calculated as Market Value per Share / Earnings per Share. For example, suppose that a company is currently trading at $\$ 43$ a share and its earnings over the last 12 months were $\$ 1.95$ per share. The price earnings ratio for the stock could then be calculated as $43 / 1.95$, or 22.05 .

\begin{tabular}{lll}
\hline Company & Age & Price earnings ratio \\
\hline Microsoft & 48 & 27.92 \\
Walmart & 54 & 29.69 \\
Oracle & 59 & 27.69 \\
Dell & 38 & 37.92 \\
eBay & 36 & 73.06 \\
Nike & 65 & 9.63 \\
Marvell Technology Group & 42 & -52.96 \\
Intel & 74 & 27.14 \\
Carnival & 49 & 20.46 \\
KB Home & 70 & 8.33 \\
International Rectifier & 49 & -22.87 \\
Estee Lauder & 70 & 25.63 \\
Apple & 48 & 98.56 \\
Broadcom & 44 & -5.92 \\
Danaher & 47 & 20.72 \\
Sears Holdings & 41 & 13.45 \\
FedEx & 59 & 22.69 \\
CitiGroup & 70 & 12.16 \\
Wynn Resorts & 61 & -29.77 \\
Bank of America & 56 & 10.06 \\
\hline
\end{tabular}

Table 2: The data on $X$ and $Y$.

An estimate of $P$ based on (1) is 0.418 . This means that nearly 42 percent of the pairs of companies are positively ordered in the sense that older the CEO the greater the price earnings ratio. 


\begin{tabular}{ll}
\hline Method & 95 percent interval \\
\hline Wald method & $(0.348,0.489)$ \\
Agresti and Coull (1998)'s method & $(0.349,0.488)$ \\
Arcsine method & $(0.349,0.489)$ \\
Wilson (1927)'s method & $(0.351,0.490)$ \\
Clopper and Pearson (1934)'s method & $(0.350,0.495)$ \\
Jackknife method & $(0.377,0.459)$ \\
\hline
\end{tabular}

Table 3: 95 confidence intervals for $P$.

95 percent confidence intervals for $P$ based on Table 1 are given in Table 3 . We see that the shortest confidence interval is by the jackknife method. The second shortest confidence intervals are due to Agresti and Coull (1998)'s method and Wilson (1927)'s method. The third shortest confidence interval is by the arcsine method. The fourth shortest confidence interval is by Wald method. The confidence interval due to Clopper and Pearson (1934)'s method is the widest.

\section{References}

[1] Agresti, A. and Coull, B. A. (1998). Approximate is better than 'exact' for interval estimation of binomial proportions. The American Statistician, 52, 119-126.

[2] Anderson, T. W. and Darling, D. A. (1954). A test of goodness of fit. Journal of the American Statistical Association, 49, 765-769.

[3] Balakrishnan, N., Kannan, N. and Nagaraja, H. N. (2005). Advances in Ranking and Selection, Multiple Comparisons, and Reliability: Methodology and Applications. Birkhäuser Boston, Boston.

[4] Berry, K. J., Johnston, J. E. and Mielke, P. W., Jr. (2014). A Chronicle of Permutation Statistical Methods. 1920-2000, and Beyond. Springer Verlag, New York.

[5] Clopper, C. and Pearson, E. S. (1934). The use of confidence or fiducial limits illustrated in the case of the binomial. Biometrika, 26, 404-413.

[6] Kahneman, D. (2012). Thinking, Fast and Slow. Penguin, New York.

[7] Kolmogorov, A. (1933). Sulla determinazione empirica di una legge di distribuzione. Giornale dell'Istituto Italiano degli Attuari, 4, 83-91.

[8] Smirnov, N. (1948). Table for estimating the goodness of fit of empirical distributions. Annals of Mathematical Statistics, 19, 279-281.

[9] Wilson, E. B. (1927). Probable inference, the law of succession, and statistical inference. Journal of the American Statistical Association, 22, 209-212. 